\title{
Existential interventions for adolescent suicidality: Practical interventions to target the root causes of adolescent distress
}

\author{
Ragan Lybbert \\ Brigham Young University - Provo \\ Samuel Ryland \\ Brigham Young University - Provo \\ Roy A. Bean \\ Brigham Young University - Provo, roy_bean@byu.edu
}

Follow this and additional works at: https://scholarsarchive.byu.edu/facpub

Part of the Other Social and Behavioral Sciences Commons

\section{Original Publication Citation}

*Lybbert, R., *Ryland, S., \& Bean, R. A. (2019). Existential interventions for adolescent suicidality: Practical interventions to target the root causes of adolescent distress. Children and Youth Services Review, 100, 98-104.

\section{BYU ScholarsArchive Citation}

Lybbert, Ragan; Ryland, Samuel; and Bean, Roy A., "Existential interventions for adolescent suicidality: Practical interventions to target the root causes of adolescent distress" (2019). Faculty Publications. 5031.

https://scholarsarchive.byu.edu/facpub/5031

This Peer-Reviewed Article is brought to you for free and open access by BYU ScholarsArchive. It has been accepted for inclusion in Faculty Publications by an authorized administrator of BYU ScholarsArchive. For more information, please contact ellen_amatangelo@byu.edu. 
Discussion

\title{
Existential interventions for adolescent suicidality: Practical interventions to target the root causes of adolescent distress
}

\author{
Ragan Lybbert ${ }^{*, 1}$, Samuel Ryland ${ }^{1}$, Roy Bean \\ Brigham Young University, School of Family Life, Marriage and Family Therapy Program, United States
}

\section{A B S T R A C T}

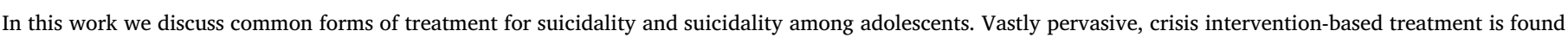

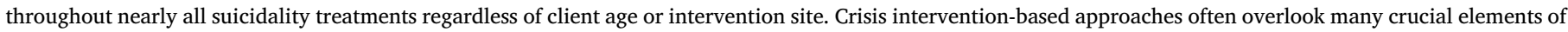

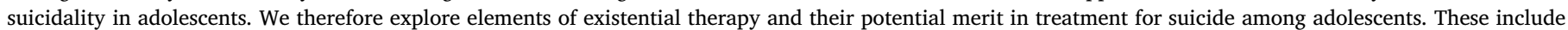

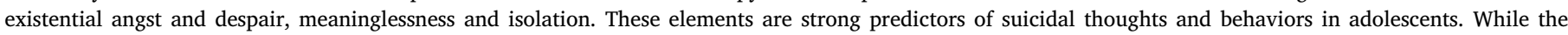

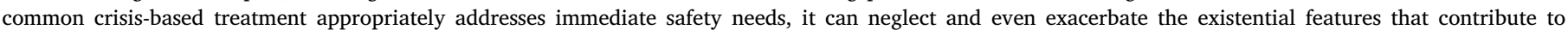

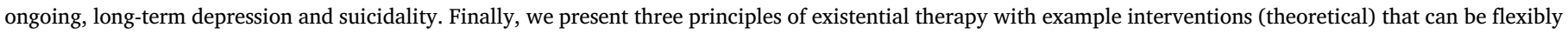

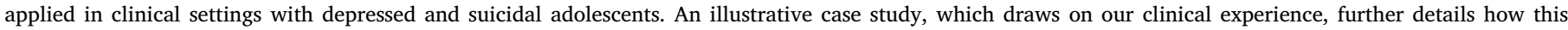
existential style might be applied in a typical clinical setting with a suicidal adolescent.

Adolescent suicide rates are alarmingly high among numerous groups and international populations. In fact, suicide was recently found to be the second-highest cause of death among adolescents and emerging adults (ages 10-24, World Health Organization, 2018). More specifically, as of 2016, the rate of suicide for people aged 15-19 years worldwide was 9.5 per 100,000 for males and 4.18 per 100,000 for females (Kõlves and De Leo, 2016). While the suicide rate is lower for the female population, females are more likely to experience suicidality and attempt suicide than males, whilst males are 3 times more likely to die by suicide (Peter \& Roberts, 2010).

Although the ratio of deaths by suicide to attempted suicides is low (ranging from 1:100 to 1:50; Husain, 1990), non-lethal suicide attempts and suicidal ideation are significant causes for concern. Suicidality is strongly correlated with depressive and bipolar disorders (Oquendo et al., 2004), and indicates a significant and problematic impairment, especially during the critical developmental period of adolescence. The U.S.-based Youth Risk Behavior Survey indicated that in the 12 months previous to the survey, $16.9 \%$ of girls and $10.3 \%$ of boys had planned a suicide attempt (Kann et al., 2014). This is an unacceptably high percentage of youth who are feeling these levels of distress and hopelessness.

According to Rogers and Soyka (2004), the underlying approach to intervening with suicidality is the crisis intervention model. These authors describe the crisis intervention model as a short-term approach that is singular in focus, dedicated to helping the person survive their crisis. These authors further indicate that a fear-based response which occurs in those responding to a person experiencing suicidality has led to a "rigid and mechanistic application of the crisis intervention model" (p. 11) which leads to said persons being "responded to from an 'expert' position focused on lethality and risk assessment, safety planning, and problem solving as opposed to a meaning focused understanding" (p.20, 2004). These approaches were developed in the 1950s and have been widely used since this time, yet suicide attempt and death by suicide rates have not decreased (Ougrin, Tranah, Stahl, Moran, \& Asarnow, 2015). Unfortunately, there is an overall lack of critical investigations of the crisis intervention approach (Singer, 2015) or other therapeutic responses to crises or suicidality (Guo \& Harstall, 2004; Roberts \& Everly, 2006; Rogers, 2012; Thomas \& Leitner, 2005).

The intention of this work, then, is twofold: first, to highlight the need for a critical investigation of the current treatment approach for adolescent suicidality; and second, to identify how existential principles and interventions might inform and add value to the treatment of adolescent suicidality. We do not identify the interventions and theoretical adjustments suggested here as a new treatment program or specific modality, nor do we aim to operationalize the concepts discussed for model testing. Instead, the principles and interventions we suggest are intended as a tangible reminder and reinforcement of generally accepted humanistic theoretical principles that are often missing from the treatment of adolescent suicidality, largely due to the stress, risks, and external pressures of working with suicidal clients.

\footnotetext{
* Corresponding author.

E-mail address: raglyb@gmail.com (R. Lybbert).

${ }^{1}$ Co-first authorship.
} 
Specific interventions are only detailed to illustrate these principles and provide clinicians with a concrete example of how the integration of existentialist principles can translate into practice.

\section{Literature review}

\subsection{Existential factors that contribute to adolescent health}

In order to conceptualize and present a better solution to the problem of adolescent suicide, we must consider the factors that contribute to it. In a study of 100 adolescents (aged 17 to 19), Rutter and Behrendt (2004) identified four primary factors that correlate with suicide risk: hopelessness, hostility, negative self-concept, and isolation. Similarly, Taliaferro and Muehlenkamp (2014) found that hopelessness and depression were significant correlates of suicidality in adolescents. Using psychological autopsies to compare 140 adolescent suicides with 131 community controls, Brent, Baugher, Bridge, Chen, and Chiappetta (1999) found that mood disorders, history of abuse, and substance abuse contributed to higher risk of suicide. Harris and Lennings (1993) similarly found that depression was the best predictor of both suicidality and suicide attempts.

While considerable attention has been given to the problem of teen suicidality and effective responses, little attention seems to have been given to some of the aforementioned primary causal factors, especially hopelessness and despair. These factors can be considered especially important given that adolescence (as a life stage) is significantly focused on processes of identity formation, which considers questions of self-concept, purpose, and the meaning of life in general (Erikson, 1968): "While a person develops their sense of identity (who they are, what they believe in, and where they are going), existential concerns should become prominent.” (Berman, Weems, \& Stickle, 2006, p. 286).

A frequent component of the identity formation and development process is existential anxiety, a core human issue in philosophy and human development theories (Damon, Menon, \& Cotton Bronk, 2003). Research suggests that issues of life and death and broader meanings around existence become salient at around high school age (Berman, Weems, \& Stickle, 2006), yet very little attention has been devoted to applying existential principles when working with adolescents (Fitzgerald, 2005). Adolescents who are actively exploring questions around their existence may experience higher levels of general anxiety and depression (Berman, Jobes, \& Silverman, 2006), which can increase risks for problematic behavior, self-harm, and suicidality, especially when the adolescent feels stalled or unable to find meaning and purpose. Researchers and clinicians are well situated to address this by developing and applying supportive interventions to help adolescents navigate this difficult process.

The connection between adolescents' existential security and their well-being (defined as an absence of problematic or self-destructive behaviors) is supported in a systemic review of research on mental health and religiosity (Wong, Rew, \& Slaikeu, 2006), which showed that teens who demonstrated higher levels of religiosity or spirituality were generally more mentally healthy. A survey of 134 high school students also found that higher levels of spiritual well-being had higher levels of existential well-being, and fewer depressive symptoms and risk-taking behaviors (Cotton, Larkin, Hoopes, Cromer, \& Rosenthal, 2005). These findings indicate that there may be a strong relationship between a clear sense of meaning and mental well-being.

Additional support for considering existential meaning in interventions of adolescent suicidal ideation is found in Berman, Weems, and Stickle (2006) who found that existential concerns were highly prevalent in a population of 140 high school adolescents, and that existential anxiety correlated with the existence of anxiety and depression. This suggests that existential exploration can be a normative task of adolescence, but also one that leads to increases in anxiety and depression. It is also worth mentioning that when adolescents have an established sense of meaning (defined as motivating purpose in daily tasks), they respond with higher academic achievement (Al-Yagon \& Margalit, 2006), healthy eating and physical activity (Brassai, Piko, \& Steger, 2011), and anticipation of future involvement in problem-solving and health-enhancing behaviors (Brassai, Piko, \& Steger, 2012). These findings suggest that supporting existential development processes in adolescents can increase healthy future-oriented behaviors in addition to preventing problematic behaviors.

\subsection{Existential despair and suicidality}

There is a well-established link between existential despair and suicidality (Tomer, Eliason, \& Wong, 2008). A study of 298 university undergraduates found that a lack of coherence (defined as a sense of confidence and purpose in daily life) was significant in predicting suicidal ideation (Edwards \& Holden, 2003). In contrast, positive indicators (i.e., purpose in life and satisfaction in life) were highly predictive of reduced suicidal ideation, even accounting for other negative psychological factors (i.e., neuroticism, depression, social hopelessness; Heisel \& Flett, 2004). Orbach, Mikulincer, Gilboa-Schechtman, and Sirota (2003) found that suicidal inpatients scored higher on measures of mental pain and lower on measures of life meaning. Problems related to meaning and existence are frequent markers of first-episode depression, with common expressions of feeling alone, feeling empty, and a confused sense of self, which in some cases leads to expressions of suicidal thoughts (Smith \& Rhodes, 2015). Wilchek-Aviad and Malka (2016) reported finding a significant negative correlation between suicidality and levels of meaning in life. These authors also reported a significant negative correlation between meaning in life and the subscales of suicidality (identified as depression, sadness and anxiety, guilt and anger). These negative correlations between meaning and suicidality (and some of its contributing factors) held true for all groups of participants, suggesting an important connection between suicidality and a sense of meaning in life.

This relationship has also been found in adolescent populations, with Kinnier, Metha, Keim, and Okey (1994) identifying a correlation between lack of meaning and suicidality in a population of high school students and inpatients. Harlow, Newcomb, and Bentler (1986) found that in cases of depression and self-derogation, females were likely to consider suicide, whereas males were more likely to consider suicide in response to meaninglessness and lack of purpose.

\subsection{Current treatment approaches for adolescent suicidality}

\subsubsection{Treatment models}

Despite the wide-spread acceptance and application of the crisis intervention model, a wide variety of theories exist for use in the treatment of adolescent suicidality. These include psychodynamic psychotherapy, problem-solving approaches, cognitive-behavioral therapy (CBT), dialectical behavior therapy (DBT), collaborative assessment and management of suicidality (CAMS), and interpersonal psychotherapy (Berman, Jobes, \& Silverman, 2006). From Berman and others' list of models and interventions, CBT was identified as the most empirically supported intervention for suicidal adolescents. However, these authors also noted that "virtually no studies have examined general clinical assessment and treatment of a range of suicidal clients in typical outpatient settings. Much of the extant treatment literature is not specific to adolescent suicidality" (p. 176).

A recent meta-analysis study of the efficacy of therapeutic interventions in reducing self-harm and suicide attempts in adolescents found that there has been no meaningful reduction in suicide death rates over the past 60 years (Ougrin et al., 2015). Studies that included a pharmaceutical adjunct were omitted from analysis in this study; however, the therapeutic interventions that were examined (including CBT, DBT, and Mentalization-based Therapy) were not shown to have a significantly different effect from treatment as usual. Whilst some of the studies reviewed and included in the meta-analysis indicated a 
significant impact of a specific model when compared to treatment as usual, none of these results have been independently replicated.

\subsubsection{The crisis intervention approach}

Taking a step back from specific modalities used in treatment of suicidality reveals a different focus. The crisis intervention approach is described as having a singular focus on keeping the suicidal person alive through risk assessment and safety planning. The main steps of this approach include establishing rapport, assessing risk and developing a safety plan. This is followed by optional responses, which include creating a 'no-suicide' contract, environmental modification, involving family members, or hospitalization when necessary (Thomas \& Leitner, 2005). A sense of urgency and fear of liability is often apparent in this approach among those who are responding to the client, many of whom may not have therapeutic training and experience (Rogers \& Soyka, 2004).

Crisis intervention has been placed at the heart of intervention for suicidality (Rogers \& Soyka, 2004) and is used in almost every treatment environment imaginable; including telephone hotlines, outpatient settings, hospitals, community health centers, and homeless shelters (Granello, 2015). Thomas and Leitner (2005) indicate that the crisis intervention model has been the primary treatment approach to suicidality in the US since the 1950s. Yet, despite its widespread prevalence, "there is relatively little research on crisis intervention" (Singer, 2015, p. 299) and little or no evidence to speak to its effectiveness in treating suicidality (Guo \& Harstall, 2004; Roberts \& Everly, 2006; Rogers, 2012; Thomas \& Leitner, 2005). Despite a growing market of popular and evidence-based mental health treatment modalities, Rogers and Soyka (2004) suggest that the crisis intervention model is ingrained in the majority, or perhaps all modalities used in treating active suicidality. This is concerning considering Thomas and Leitner's observation that there is a complete lack of supporting evidence for the effectiveness of the crisis intervention model (2005).

Rogers and Soyka (2004) highlight two additional concerns with the vast dissemination of the crisis intervention approach: (a) It has distracted clinicians and researchers from developing more effective models for treating suicidality by unintentionally feeding the social stigma that suicide is a frowned-upon subject; and (b) It creates distance between the intervenor and the person demonstrating signs of suicidal ideation. Thomas and Leitner share a similar viewpoint:

The crisis intervention model offers little in the way of prescribing the manner in which [its] steps and actions are to be carried out, thus allowing for multiple possible interpretations of the model. The typical interpretation of the model is one in which the crisis interventionist is assertive, active, and aggressive. Leenaars (1994), for example, likens the activity of a crisis intervention worker to that of a cardiologist in an emergency unit. This metaphor is consistent with the belief that the role of the crisis interventionist is to take charge of the situation and take over for the person, who is rendered weak and/or helpless in the face of the crisis, to fix the problem or repair the person. This metaphor is consistent with the depiction of the crisis interventionist in most of the literature. (2005, p. 146).

Rogers and Soyka summarize their concerns, stating that wholesale adoption of the crisis intervention model has led to a narrowly focused response to this complex issue, and that the expert role taken by the intervenor tends to put the person seeking help in a one-down position. This can have a dehumanizing effect-at the very least, it creates distance between the person seeking help and the intervenor-further isolating a suicidal person from social support. These unintentional side effects of the model create a power imbalance and may communicate that suicidality is incomprehensible or illogical, a sign of personal frailty, or that the topic is a shameful one that must be quickly and quietly addressed and then dismissed (2004). Finally, while there may be some hopeful evidence for short-term effects, there is no substantial evidence for the long-term efficacy of treatments based on the crisis intervention approach (Roberts \& Ottens, 2005).

It would be unfair to suggest that anyone using the crisis intervention approach inevitably acts in a dehumanizing or dismissive manner; we can be confident that many respondents are adept at addressing urgent safety needs with utmost care and respect for the individual. Our concern is that the systemic focus on crisis management in suicide response has shifted attention away from our enduring ethical respect for the individual, and that conscious consideration of the underlying human experiences leading to suicidality can help correct this balance.

\subsubsection{A need to adapt the crisis intervention model}

According to Goldman-Mellor et al. (2014) and the World Health Organization (2018), among the strongest risk factors, if not the strongest risk factors of a future suicide attempt, is a prior suicide attempt. This predictive factor of suicide attempts and deaths by suicide suggests a need for adaptation to the current models for treatment. Appropriately, the primary goal and focus of the crisis intervention model is to keep suicidal individuals alive. However, the forcefully directive and clinician-as-the-expert stylistic approach inherent to the crisis intervention model does not fit what suicidal clients find or believe would be most helpful (Thomas \& Leitner, 2005). Berman, Jobes, and Silverman (2006) point out most adolescents who are suicidal will likely need multiple types of interventions, including psychotherapy, administration of appropriate medication, family therapy, activation of peers and the teen's community, as well as spiritual and existential interventions.

We agree with Berman, Jobes, and Silverman's point that therapists must be directive in that clinicians recognize the urgency and importance of suicidality (Berman, Jobes, and Silverman, 2006) without becoming forcefully directive and non-collaborative (Thomas \& Leitner, 2005). We believe a more constructivist and integrative approach to the crisis intervention model is needed. More specifically, we believe that incorporating elements of existentialism would address many of the root causes of suicidality, whilst simultaneously helping the suicidal adolescent feel valued and validated. The application of existential principles could promote the exploration and development of meaning within the therapeutic relationship, especially relative to behaviors and factors related to suicidality, and focus on fostering a safe and affirming therapeutic alliance (Rogers \& Soyka, 2004).

\subsection{Existentialism, meaning, and suicidality}

There are a number of theorists who argue that suicidality is related to existential issues and/or the application of existential interventions in working with individuals experiencing suicidality (Harlow et al., 1986; Heisel \& Flett, 2004; Kinnier et al., 1994; Maris, 1989; Orbach et al., 2003; Rogers \& Soyka, 2004; Rutter \& Behrendt, 2004; Smith \& Rhodes, 2015; Tomer et al., 2008). Blair (2004), Ellsworth (1999), and Shumaker (2017) each explore various elements through which existential therapy guides and aids therapists in helping adolescents find meaning in and through their depression, existential dread, and/or existential anxiety. It is our stance that the presented evidence for the potential efficacy of existential interventions on adolescent suicidality and the abundant theoretical discussion on the topic provide support for existential interventions to be included in interventions and research seeking to establish effective treatments for adolescent suicidality.

\subsection{Applying existential interventions to suicidality}

\subsubsection{Crisis treatment model}

Yalom and Josselson (2014) state that existential therapy is not intended to be a stand-alone theory, but rather one that can and should be integrated into all therapeutic models. In advocating for change concerning suicide interventions, we don't intend to throw the proverbial baby out with the bathwater: if any method, including the crisis 
intervention model, is an effective means in preventing suicidal behavior and increasing adolescents' safety, even if only for the short-term, it should be used. Instead, we propose that: (a) existential therapy be applied as an alternative to the crisis intervention model when the assessment of suicide risk is low enough to preclude crisis intervention (i.e. the risk of self-harm is assessed as low) and, (b) existential therapy is integrated into the crisis intervention model in situations where selfharm is more likely. The latter approach could compensate for the potentially dehumanizing and isolating effects of the crisis intervention model, while simultaneously addressing immediate self-harm threats and safely processing the adolescent's underlying motivations and distress. We believe it is important to develop a treatment which not only addresses the immediate safety needs of suicidal adolescents, but also the underlying factors that contribute to adolescent suicidality.

An example of this hybrid approach might be to conduct an assessment to help the clinician understand the immediate risk of suicide, and if necessary, engage in the safety planning mandated by the crisis intervention model (discuss triggers, identify support persons and systems, and practicing grounding techniques). While addressing immediate safety concerns and throughout treatment, the therapist focusses on developing a therapeutic alliance with the client. After safety has been established, the therapist can then gently explore the underlying existential angst(s) contributing to her/his desires to escape suffering through death. The CAMS assessment mentioned earlier serves as an example of this collaborative, alliance-based approach (Berman, Jobes, and Silverman, 2006). Collaboration with the client in assessment and safety planning could mitigate some of the problematic elements of isolation and dehumanization inherent in the crisis intervention model by "develop[ing] a shared phenomenological understanding of the patient's suicidality" (p. 192, Berman, Weems, \& Stickle, 2006). When the client feels that their experience and input is validated and incorporated into safety planning, and that the therapist is interested in not only keeping them alive, but also in addressing the internal experiences contributing to their suicidality, it seems likely that the therapeutic alliance will strengthen and that long-term outcomes will improve.

\subsubsection{Principles of existential therapy}

Existential therapy consists of philosophical core principles that can be applied or adapted in several different ways. Here we present three principles of existential therapy, each accompanied with a practical intervention application for use with suicidal adolescents. These principles and techniques are based on existential techniques developed by Shumaker (2017).

1.5.2.1. Follow the client. When discussing suicidality with clients, allow the client to lead. Work in unison with the client, collaborating with them instead of dictating to them from a so-called "one-up" or expert position. This is facilitated by the therapist-aware of the stigma inherent in discussions around suicidality, especially in the crisis intervention response (Rogers \& Soyka, 2004)—providing an environment of safety and non-judgment so that the client can be honest and open in her/his disclosure. Shumaker (2017) promotes the importance of a clinician's willingness to find meaning where others (including the client) may not see it, following the client's presented experience instead of imposing her/his own. This kind of following requires a focused presence, described by Schneider (2015) as a "palpable - immediate, kinesthetic, affective, and profound attention" (p. 60). As the therapist builds trust and openness through their careful attention, they can 'invoke the actual' (Schneider, 2015) by identifying underlying emotions and experiences hinted at in the client's presentation. Conversely, if the client feels preemptive judgment from the clinician during (or after) disclosure, they are likely to close down and avoid further sharing. One might suggest that the therapist is metaphorically willing to take the hand of the client while together they 'stare into the abyss', as Nietzsche phrases the existential experience (Nietzsche and Kaufmann, 1989). Or as Yalom and Josselson (2014) suggest, an existential therapist must be "willing to walk unflinchingly with patients through life's deepest and most vexing problems" (p. 265).

1.5.2.2. Example intervention: meaning from creativity. Adolescent clients may describe themselves as "stuck" or "stalled", feelings that correspond to blocked intentionality (inability to translate meaning into action) causing depression and anxiety (Bugental, 1987). Shumaker (2017) suggests that meaning can be explored and expressed by tapping into the creative outlets and media adolescents engage in. This can be done with any effort made by the adolescent to be creative, no matter how trivial it may seem. The clinician should be open-minded, identifying non-traditional creativity in their clients. This might include how the client dresses, interest in sports of any kind, writing in journals, doodling, photography, participation in social media, etc. According to Shumaker, participation in video games can be an unexpectedly effective means of finding meaning and identity patterns in an adolescent's experience.

1.5.2.3. Respect for the client (a strengths-based approach). Existential therapy aligns with humanistic principles of respect for the client and recognition of their intrinsic worth as a human being. This recognition is potentially neglected in the crisis response approach, where the focus is primarily on fixing or preventing the client's problematic behavior. Adolescents can be more sensitive to being treated as problems rather than people, especially if they have already manifested other depressive or anti-social symptoms as precursors to suicidality.

The existential therapist can subvert this narrative by consistently communicating their perception of the adolescent client's value verbally and non-verbally. The therapist can thank the client for their contributions to therapy or for teaching valuable lessons from the experiences they share. An existential therapist might highlight strengths and capabilities that the adolescent has demonstrated in being able to survive and even thrive in some areas despite the problems they are facing. This unconditional positive regard, as Carl Rogers (1992) named it, must be genuine. Existential therapy requires reflection and personal adjustment on the part of the therapist, which may be supported by targeted supervision.

1.5.2.4. Example intervention: the hero metaphor. As a potential application of this principle of respecting the client, "The Hero Metaphor' is suggested by Shumaker (2017). The therapist identifies and suggests courage and heroism in their dialogue with the client, reframing and developing terminology to support a new narrative. This new narrative often describes the adolescent as being in the midst of a great journey in which they have experienced highs and lows, and in which they are now in a very low point. The adolescent might compare this narrative to other cultural narratives they are familiar with, which often describe a hero's journey that takes them through dark times towards eventual success. The narrative identifies the possibility that things will improve over time.

1.5.2.5. Finding meaning in suffering. One of the core processes in existential therapy is developing the client's capacity to find meaning in suffering. Borrowing from eastern philosophies that suggest acceptance of the idea that 'life is suffering', and Viktor Frankl's logotherapy (developed in response to his experiences in a World War II concentration camp), this process critiques the common western assumption that mental health is related to increasing positive experiences and reducing negative experiences-an implied assumption of the crisis response approach-and a potentially demotivating pressure in the face of persistent negative experience.

The way in which a person experiences suffering is fundamentally related to their character and value system. A suicidal adolescent might relate their hatred of the corruption and selfishness they see in 
politicians and world leaders - a train of thought that might lead to helplessness and despair. Applying existential principles, a therapist might reframe this as a reflection of the adolescent's positive values of fairness and social justice- that the pain they feel is related to their care and empathy for those who are poorly treated. The conversation can then take a new direction, focusing on the client's ability to see their values as a positive addition in a less-than-ideal world.

It can be tempting to dismiss the pain and suffering from adolescents: all adults have gone through their own adolescence and, in hindsight, may have re-evaluated their pain and suffering as less significant than they felt at the time. Any evaluation of the relative merit of the adolescent's suffering can only hurt the therapeutic relationship and be interpreted as dismissive and invalidating. The point of existentialism is not to dismiss the pain, but to embrace it and learn from it.

1.5.2.6. Example intervention: values from suffering. This intervention is as simple as deriving the client's values from their expressions of suffering. When the client says they feel like they are treated like a baby, you can infer that freedom and respect are important values to them. When a client says that they hate their teachers, you can explore more specifics of what is bothering them: perhaps they feel judged unfairly and stereotyped: from this you can infer values of nonjudgment and open-mindedness. You might extend this further to ask them what kind of teacher they would want to be, encouraging awareness of value-based action and future possibilities.

The awareness of values can inspire new possibilities for action. Here an existential therapist might borrow from Frankl's primary focus on retaining the capacity to choose in a confined situation (Frankl, 1969): how might the client act, in small and large ways, on the values identified in therapy? This can enhance the adolescent's internal locus of control and encourage thinking about future possibilities.

This concept might also be conceptualized as living authentically. Chessick (1996) illustrated an application of encouraging authenticity in psychotherapy with adolescents through a case example: when a teen girl presented with considerable depression and an eating disorder, Chessick avoided focus on her symptoms and instead focused on her interest in poetry (which her parents had tried to discourage). Chessick framed the therapy around the client's ambitions and developing her sense of capacity to resolutely enact these ambitions. After several months, her symptoms of depression and evidence of the eating disorder had abated, and the client continued to pursue her ambitions in ways that avoided further parental conflict. This example represents the possibility that suicidal adolescents often have things to live for, but for some reason or reasons have felt unable to act on them. Existential therapy can help identify these values and create a sense of possibility around them.

\subsection{Involving family in treatment}

In the comprehensive list of treatments applied to adolescent suicidality, Berman, Jobes, and Silverman (2006) provided limited information on systemic or familial based interventions and no specific theories named for these categories. Yet the family system contributes strongly to the adolescent's experience of depression and suicidality (Brent \& Maalouf, 2009) and parental behaviors of control or rejection towards adolescents increase the risk of depression (McLeod, Weisz, \& Wood, 2007; Rapee, 1997). Additionally, adolescents experiencing clinical depression are more likely to demonstrate insecure attachments towards their parents (Brumariu \& Kerns, 2010). Despite this evidence that the familial context contributes to depression and other contributing factors to adolescent suicidality, there are few family-based treatment approaches intended for adolescent suicidality (Hunt, Sandoval-Barrett, \& Diamond, 2017). Yet, there is already some preliminary evidence that Attachment-Based Family Therapy (ABFT) could be helpful in treating suicidal adolescents. In a randomized control trial
ABFT was compared with a treatment as usual control group for suicidal adolescents. $87 \%$ of clients in the ABFT treatment group setting met criteria for clinical recovery from suicidality, while only $52 \%$ in the treatment as usual group met the same criteria (Diamond et al., 2010).

Because ABFT has been developed for use with adolescents with depression (Diamond, Diamond and Levy, 2014; a strong correlate of existential suffering and a frequent precursor to suicidality), and because of the already existent evidence for the efficacy of ABFT with suicidal teens, we believe that it is an excellent candidate to be used alongside an existential approach. Attachment theory directly addresses themes of acceptance, safety and security, which help mediate processes of existential suffering. Thus, the previous discussion of an existential therapeutic stance can also apply to the family therapy setting. Our review of suicidality literature suggests that little attention has been devoted to family-based interventions on suicidality. Though it is beyond the scope of this paper's focus to develop and elaborate on what family-based existential interventions might look like, we believe research in this area deserves further attention and that ABFT is an excellent initial candidate for said research.

\section{Case study}

The following fictional case example has been derived from experience with multiple clients to illustrate dimensions of the therapeutic stance and existential interventions in a clinical setting with an adolescent client presenting with suicidality. Principles and interventions described above are identified as they are applied. Any names used have no relation to real clients we have seen. Furthermore, the case study is intended as an illustrative conceptualization of existentialism used to address adolescent suicidality; it is not intended to be a form of a manualized treatment modality.

Alex, 16, is referred to outpatient treatment by a local hospital after five days in an inpatient facility. Alex had attempted to overdose using his mother's sleeping pills, but his mother found him and took him to the local emergency room, where he was then referred to an acute mental health care facility.

In the first and ongoing sessions, the therapist carefully assesses Alex's current thoughts and feelings related to suicidality and self-harm and works alongside Alex to identify risks and safety measures. As they begin the first session, Alex said he feels that there is no point to life, and that he can't think of a good reason not to jump off the overpass near his school. Alex reports that he has felt depressed for a long time.

The therapist invokes 'presence' (Schneider, 2015) by asking Alex to describe how he is feeling right now. As Alex starts to describe, the therapist keeps asking questions to explore Alex's experience. The therapist is leaning forward in his chair and reflecting on the salient descriptions Alex provides. If the therapist takes notes, he asks for Alex's permission, and explains that he wants to remember any important things that Alex says. The therapist tries to 'invoke the actual' (Schneider, 2015) by cautiously using analogies or deepening words to help Alex identify his experience, but quickly backtracks if these don't resonate (principle one: follow the client-the therapist gently explores and allows the client to describe their experience in their own words).

Over the course of therapy, as Alex starts to describe his intense anger at how 'uncaring' everyone is, the therapist maintains an open posture and warm expression. The therapist reflects back and asks questions about the anger in a way that demonstrates acceptance and validation (principle two: respect for the client-the therapist communicates positive regard, even when responding to intense emotions).

Alex starts to describe meaninglessness, using words like 'there's no point' and 'nothing will ever change'. Instead of challenging these thoughts, the therapist asks Alex what this emptiness feels like and how long he has felt it. The therapist even carefully guesses at how this might feel for Alex. The therapist shows his own emotional response of sadness for the feelings that Alex is having.

The therapist asks what kinds of things Alex does when he feels this 
way. Alex mentions he plays a lot of video games. The therapist explores what kind of video games Alex likes, identifying themes, character identification, achievement goals, perspective-taking, and emotional responses that Alex has to these games. The therapist explores how Alex plays these games: for how long, in what order, whether he explores or acts quickly, etc. Alex says he likes to explore the world within the game, taking his time to complete quests and often getting side-tracked. The therapist acknowledges and affirms Alex's curiosity and embracement of new environments and connects this to why he might feel so trapped in his current environment (example intervention one: meaning from creativity - the therapist responds without judgment to the creativity and meaning manifest in the client's gaming behaviors).

The therapist asks Alex to further describe this feeling of being trapped and its development over time. Alex talks about being a curious, exploring child, but that when his family moved to a small town, he felt isolated, and started to spend a lot more time in his room. Alex described that he started to feel disinterested in the world around him, and just wanted to get away from it all. The therapist refers to Alex's curiosity, and frames how his current isolation (in the small town and then in his bedroom), might feel so painful to a curious explorer. The therapist wonders aloud what this experience of being stuck in a small town, with not much to do, is teaching him about himself and his future. The therapist also wonders aloud how this 'curious explorer' will change when he is reintroduced to the wider world, i.e. what lessons he might take from his current sadness. The therapist asks Alex about his thoughts on this (example intervention two: the hero metaphor-the therapist reframes the client's narrative of suffering as an important development in their life).

Alex further describes how he is being bullied at his school. After their move to the small town, Alex had a hard time making friends, and felt that there were a few students whose only purpose was to make his life miserable. The therapist openly explores Alex's experience of this bullying, and the subsequent feelings and negative messages associated with it. The therapist asks Alex how he feels about bullying in general, and what he feels when he sees other people getting bullied. Alex says he feels hatred, that he just wishes he could 'smash' the bullies. The therapist explores this hatred, this desire to hurt the bullies, and asks Alex why bullying is wrong. Alex says it hurts, it's unfair, no one deserves to be treated like that. The therapist reframes these expressions as values Alex holds: fairness, respect, care for others. The therapist asks Alex about other areas in his life where Alex feels these values. The therapist identifies Alex as a caring individual who wants everyone to be treated with care and respect, and that a large part of his pain exists as he sees the violation of these values (example intervention three: values from suffering - the therapist identifies values manifest in the client's emotional responses). The therapist wonders aloud how these values might be expressed in Alex's future, i.e. what difference they have made to others, and what difference they could make to the world in general (principle three: finding meaning in suffering-the therapist identifies meaning behind identified values by expanding the client's frame of reference in possible application of these values).

At the end of each session of therapy, the therapist identifies one or two key things that he learned from Alex, and sincerely thanks him for these lessons. The therapist recognizes that these teachings are coming from a painful place, and thus he sees them as valuable and appreciates that they stem from Alex's suffering.

Throughout the course of therapy, Alex starts to describe his negative experiences within a larger frame of his life's journey, and slowly starts to express more hope for his future. Although he still regularly feels 'trapped' and depressed, he also identifies with values of care and exploration, and starts to describe things that he does regularly that reflect those values. After ensuring that Alex has a well-defined safety plan and that suicidal thinking has subsided, therapy is discontinued. In the final session, the therapist reflects on all that he has learned from Alex throughout the process, thanks him for his courageous participation, and expresses sincere hope that Alex will find meaning and purpose in his future, whatever it may bring.

\section{Conclusion}

The rate of adolescent suicide attempts and completions is alarming. Despite a concerted effort to manage this crisis over the last 60 years, we have generally not seen significant reductions in suicide rates. Of further concern is the lack of evidence-supported treatment models for the treatment of suicidality of all populations, including adolescents. Despite a lack of evidence, the crisis intervention response to suicidality seems to have been adopted almost universally. This model does not take into consideration a number of elements closely tied to suicidality among adolescents.

Existential therapy practices are often developed as principles and orientations; their implied flexibility in adaptation to the client's unique development of meaning makes them less amenable to operationalization and model development. This may partly explain the lack of outcome research on existential interventions in psychotherapy. New developments in process research may provide more opportunities to explore how existential principles operate in session and influence client outcomes. We hope this paper will inspire more focused research efforts in this area. We are also aware that adolescents are not a homogenous group. Although the development of meaning is often acknowledged as a universal process, the exploration and expression of this meaning may occur differently in various cultures and subgroups. We recommend that practitioners review sources referenced here or elsewhere to identify how they can integrate existential principles and ideas into their current models and approaches, and with different populations of clients.

Camus and O'Brien (1975) said, "seeking what is true is not seeking what is desirable" (p. 43), and "there is scarcely any passion without struggle" (p.70). Existential angst and despair can be stepping stones to a life imbued with satisfaction and meaning, but without caring guidance adolescents and young adults can become mired in depression and hopelessness that often leads to suicidality.

We believe there is a strong mandate to address more directly the existential concerns that contribute to adolescent experiences of suicidality. It is our hope that these proposed principles and interventions will encourage further consideration of and attention to potential applications of existential therapy to adolescent populations, especially where suicidality is present.

\subsection{Summary}

In this work we discuss common forms of treatment for suicidality and suicidality among adolescents. Vastly pervasive, crisis interventionbased treatment is found throughout nearly all suicidality treatments regardless of client age or intervention site. Crisis intervention-based approaches often overlook many crucial elements of suicidality in adolescents. We therefore explore elements of existential therapy and their potential merit in treatment for suicide among adolescents. These include existential angst and despair, meaninglessness and isolation. These elements are strong predictors of suicidal thoughts and behaviors in adolescents. While the common crisis-based treatment appropriately addresses immediate safety needs, it can neglect and even exacerbate the existential features that contribute to ongoing, long-term depression and suicidality. Finally, we present three principles of existential therapy with example interventions that can be flexibly applied in clinical settings with depressed and suicidal adolescents. A sample case study, which draws on our clinical experience, further details how this existential style might be applied in a typical clinical setting with a suicidal adolescent. 


\section{References}

Al-Yagon, M., \& Margalit, M. (2006). Loneliness, sense of coherence and perception of teachers as a secure base among children with reading difficulties. European Journal of Special Needs Education, 21, 21-37. https://doi.org/10.1080/ 08856250500268619 .

Berman, A. L., Jobes, D. A., \& Silverman, M. M. (2006). Adolescent suicide: Assessment and intervention. Washington, DC: American Psychological Association.

Berman, S. L., Weems, C. F., \& Stickle, T. R. (2006). Existential anxiety in adolescents: Prevalence, structure, association with psychological symptoms and identity development. Journal of Youth and Adolescence, 35, 285-292. https://doi.org/10.1007/ s10964-006-9032-y.

Blair, R. G. (2004). Helping older adolescents search for meaning in depression. Journal of Mental Health Counseling, 26, 333-347. https://doi.org/10.17744/mehc.26.4 w8u9h6uf5ybhapyl.

Brassai, L., Piko, B. F., \& Steger, M. F. (2011). Meaning in life: Is it a protective factor for adolescents' psychological health? International Journal of Behavioral Medicine, 18, 44-51. https://doi.org/10.1007/s12529-010-9089-6.

Brassai, L., Piko, B. F., \& Steger, M. F. (2012). Existential attitudes and Eastern European adolescents' problem and health behaviors: Highlighting the role of the search for meaning in life. The Psychological Records, 62, 719-734.

Brent, D. A., Baugher, M., Bridge, J., Chen, T., \& Chiappetta, L. (1999). Age- and sexrelated risk factors for adolescent suicide. Journal of the American Academy of Child \& Adolescent Psychiatry, 38, 1497-1505. https://doi.org/10.1097/00004583199912000-00010.

Brent, D. A., \& Maalouf, F. T. (2009). Pediatric depression: Is there evidence to improve evidence-based treatments? Journal of Child Psychology and Psychiatry, 50, 143-152. https://doi.org/10.1111/j.1469-7610.2008.02037.x

Brumariu, L. E., \& Kerns, K. A. (2010). Parent-child attachment and internalizing symptoms in childhood and adolescence: A review of empirical findings and future directions. Development and Psychopathology, 22, 177-203. https://doi.org/10.1017/ S0954579409990344.

Bugental, J. F. T. (1987). The art of the psychotherapist. New York, London: Norton.

Camus, A., \& O'Brien, J. (1975). The myth of Sisyphus. London: Penguin.

Chessick, R. D. (1996). Heidegger's" authenticity" in the psychotherapy of adolescents. American Journal of Psychotherapy, 50, 208.

Cotton, S., Larkin, E., Hoopes, A., Cromer, B. A., \& Rosenthal, S. L. (2005). The impact of adolescent spirituality on depressive symptoms and health risk behaviors. Journal of Adolescent Health, 36, 529. https://doi.org/10.1016/j.jadohealth.2004.07.017.

Damon, W., Menon, J., \& Cotton Bronk, K. (2003). The development of purpose during adolescence. Applied Developmental Science, 7, 119-128. https://doi.org/10.1207/ S1532480XADS0703_2.

Diamond, G. S., Diamond, G. M., \& Levy, S. A. (2014). Attachment-based family therapy for depressed adolescents. Washington, DC, US: American Psychological Association.

Diamond, G. S., Wintersteen, M. B., Brown, G. K., Diamond, G. M., Gallop, R., Shelef, K., \& Levy, S. (2010). Attachment-based family therapy for adolescents with suicidal ideation: A randomized controlled trial. Journal of the American Academy of Child \& Adolescent Psychiatry, 49, 122-131. https://doi.org/10.1097/00004583-201002000 00006.

Edwards, M. J., \& Holden, R. R. (2003). Coping, meaning in life, and suicidal manifestations: Examining gender differences. Journal of Clinical Psychology, 57(12), 1517-1534. https://doi.org/10.1002/jclp.10206.

Ellsworth, J. A. (1999). Today's adolescent: Addressing existential dread. Adolescence, 34, 403.

Erikson, E. H. (1968). Identity: Youth and crisis (no. 7). New York, NY: WW Norton \& Company.

Fitzgerald, B. (2005). An existential view of adolescent development. Adolescence, 40. https://doi.org/10.1016/S0168-9525(99)01898-3.

Frankl, V. E. (1969). The will to meaning: Foundations and applications of logotherapy. New York, NY: World Publishing Company.

Goldman-Mellor, S. J., Caspi, A., Harrington, H., Hogan, S., Nada-Raja, S., Poulton, R., \& Moffitt, T. E. (2014). Suicide attempt in young people: A signal for long-term health care and social needs. JAMA Psychiatry, 71, 119-127. https://doi.org/10.1001/ jamapsychiatry.2013.2803.

Granello, D. H. (2015). Suicide crisis intervention. In K. Yeager, \& A. Roberts (Eds.). Crisis intervention handbook: Assessment, treatment, and research (pp. 299-347). New York, NY: Oxford University Press.

Guo, B., \& Harstall, C. (2004). For which strategies of suicide prevention is there evidence of effectiveness? Copenhagen: WHO Regional office for Europe, Health Evidence Network Report. http://www.euro.who.int/_data/assets/pdf_file/0010/74692/ E83583.pdf, Accessed date: 4 November 2018.

Harlow, L. L., Newcomb, M. D., \& Bentler, P. M. (1986). Depression, self-derogation, substance use, and suicide ideation: Lack of purpose in life as a mediational factor Journal of Clinical Psychology, 42, 5-21. https://doi.org/10.1016/S0360-3016(99) 00284-9.

Harris, T. E., \& Lennings, C. J. (1993). Suicide and adolescence. International Journal of Offender Therapy and Comparative Criminology, 37, 263-270. https://doi.org/10. $1177 / 0306624$ X9303700307.

Heisel, M. J., \& Flett, G. L. (2004). Purpose in life, satisfaction with life, and suicide ideation in a clinical sample. Journal of Psychopathology and Behavioral Assessment, 26, 127-135. https://doi.org/10.1023/B:JOBA.0000013660.22413.e0.

Hunt, Q., Sandoval-Barrett, J., \& Diamond, G. (2017). Attachment-based family therapy with suicidal adolescents: An overview. Psychiatric Annals, 47, 412-415. https://doi. org/10.3928/00485713-20170707-01.

Husain, S. A. (1990). Current perspective on the role of psychosocial factors in adolescent suicide. Psychiatric Annals, 20, 122-127. https://doi.org/10.3928/0048-571319900301-06

Kann, L., Kinchen, S., Shanklin, S. L., Flint, K. H., Hawkins, J., Harris, W. A., ... Whittle, L.
(2014). Youth risk behavior surveillance-United States, 2013. Morbidity and mortality weekly report. Surveillance Summaries, 63, 1-168.

Kinnier, R. T., Metha, A. T., Keim, J. S., \& Okey, J. L. (1994). Depression, meaninglessness, and substance abuse in "normal" and hospitalized adolescents. Journal of Alcohol and Drug Education, 39, 101-111.

Kõlves, K., \& De Leo, D. (2016). Adolescent suicide rates between 1990 and 2009: Analysis of age group 15-19 years worldwide. Journal of Adolescent Health, 58, 69-77. https://doi.org/10.1016/j.jadohealth.2015.09.014.

Leenaars, A. A. (1994). Crisis intervention with highly lethal suicidal people. In A. A. Leenaars, J. T. Maltsberger, \& R. A. Neimeyer (Eds.). Treatment of suicidal people (pp. 45-59). Washington, DC: Taylor \& Francis.

Maris, R. W. (1989). Suicide intervention: The existential and biomedical perspectives. In D. Jacobs, \& H. N. Brown (Eds.). Suicide: Understanding and responding: Harvard Medical School perspectives (pp. 449-458). Madison, CT: International Universities Press, Inc.

McLeod, B. D., Weisz, J. R., \& Wood, J. J. (2007). Examining the association between parenting and childhood depression: A meta-analysis. Clinical Psychology Review, 27, 986-1003. https://doi.org/10.1016/j.cpr.2007.03.001.

Nietzsche, F. W., \& Kaufmann, W. A. (1989). Beyond good and evil: Prelude to a philosophy of the future. New York, NY: Vintage Books.

Oquendo, M. A., Galfalvy, H., Russo, S., Ellis, S. P., Grunebaum, M. F., Burke, A., \& Mann, J. J. (2004). Prospective study of clinical predictors of suicidal acts after a major depressive episode in patients with major depressive disorder or bipolar disorder. American Journal of Psychiatry, 161(8), 1433-1441. https://doi.org/10.1176/appi. ajp.161.8.1433.

Orbach, I., Mikulincer, M., Gilboa-Schechtman, E., \& Sirota, P. (2003). Mental pain and its relationship to suicidality and life meaning. Suicide and Life-threatening Behavior, 33, 231-241. https://doi.org/10.1521/suli.33.3.231.23213.

Ougrin, D., Tranah, T., Stahl, D., Moran, P., \& Asarnow, J. R. (2015). Therapeutic interventions for suicide attempts and self-harm in adolescents: Systematic review and meta-analysis. Journal of the American Academy of Child \& Adolescent Psychiatry, 54, 97-107. https://doi.org/10.1016/j.jaac.2014.10.009.

Peter, T., \& Roberts, L. W. (2010). 'Bad' boys and 'Sad' girls? Examining internalizing and externalizing effects on parasuicides among youth. Journal of Youth and Adolescence, 39, 495-504. https://doi.org/10.1007/s10964-009-9498-5.

Rapee, R. M. (1997). Potential role of childrearing practices in the development of anxiety and depression. Clinical Psychology Review, 17, 47-67. https://doi.org/10.1016/ S0272-7358(96)00040-2.

Roberts, A. R., \& Everly, G. S. (2006). A meta-analysis of 36 crisis intervention studies. Brief Treatment and Crisis Intervention, 6, 10-21. https://doi.org/10.1093/brieftreatment/mhj006.

Roberts, A. R., \& Ottens, A. J. (2005). The seven-stage crisis intervention model: A road map to goal attainment, problem solving, and crisis resolution. Brief Treatment and Crisis Intervention, 5, 329-339. https://doi.org/10.1093/brief-treatment/mhi030.

Rogers, C. R. (1992). The necessary and sufficient conditions of therapeutic personality change. Journal of Consulting and Clinical Psychology, 60, 827-832. https://doi.org/ 10.1037/0022-006X.60.6.827.

Rogers, J. R. (2012). Responding to suicidal crises: The crisis intervention approach. In A Shrivastava, K. Megan, \& D. Lester (Eds.). Suicide from a global perspective: Risk assessment and management (pp. 213-218). Hauppauge, NY: Nova Science Publishers.

Rogers, J. R., \& Soyka, K. M. (2004). "One size fits all”: An existential-constructivist perspective on the crisis intervention approach with suicidal individuals. Journal of Contemporary Psychotherapy, 34, 7-22. https://doi.org/10.1023/B:JOCP. 0000010910.74165.3a.

Rutter, P. A., \& Behrendt, A. E. (2004). Adolescent suicide risk: Four psychosocial factors. Adolescence, 39, 295.

Schneider, K. J. (2015). Existential-integrative psychotherapy: Guideposts to the core of practice. New York: Routledge, Taylor \& Francis Group.

Shumaker, D. (2017). Existential-integrative approaches to treating adolescents. New York, NY: Palgrave Macmillan.

Singer, J. B. (2015). Child and adolescent psychiatric emergencies: Mobile crisis response. In K. Yeager, \& A. Roberts (Eds.). Crisis intervention handbook: Assessment, treatment, and research (pp. 299-347). New York, NY: Oxford University Press.

Smith, J. A., \& Rhodes, J. E. (2015). Being depleted and being shaken: An interpretative phenomenological analysis of the experiential features of a first episode of depression. Psychology and Psychotherapy: Theory, Research and Practice, 88, 197-209. https://doi.org/10.1111/papt.12034.

Taliaferro, L. A., \& Muehlenkamp, J. J. (2014). Risk and protective factors that distinguish adolescents who attempt suicide from those who only consider suicide in the past year. Suicide and Life-threatening Behavior, 44, 6-22. https://doi.org/10.1111/ sltb.12046.

Thomas, J. C., \& Leitner, L. M. (2005). Styles of suicide intervention: Professionals' responses and clients' preferences. The Humanistic Psychologist, 33, 145-165. https:// doi.org/10.1207/s15473333thp3302_5.

Tomer, A., Eliason, G. T., \& Wong, P. T. P. (Eds.). (2008). Existentialism and spiritual issues in death attitudes. Mahwah, NJ: Lawrence Erllbaum Associates.

Wilchek-Aviad, Y., \& Malka, M. (2016). Religiosity, meaning in life and suicidal tendency among Jews. Journal of Religion and Health, 55, 480-494. https://doi.org/10.1007/ s10943-014-9996-y.

Wong, Y. J., Rew, L., \& Slaikeu, K. D. (2006). A systematic review of recent research on adolescent religiosity/spirituality and mental health. Issues in Mental Health Nursing, 27, 161-183. https://doi.org/10.1080/01612840500436941.

World Health Organization (2018). Suicide. World Health Organization media centre fact sheets. Retrieved from http://www.who.int/mediacentre/factsheets/nn398/en/on, Accessed date: 4 March 2018.

Yalom, D. Y., \& Josselson, R. (2014). Existential Psychotherapy. In D. Wedding, \& R. J. Corsini (Eds.). Current psychotherapies (pp. 265-298). Belmont, CA: Brooks/Cole Cengage Learning. 